\title{
Corticosteroid in the Treatment of Moderate to Severe Thrombocytopenia Due to Leptospirosis
}

\author{
Shahriar Alian ${ }^{1}$; Hasan Asghari ${ }^{2}$; Narges Najafi ${ }^{1}$; Alireza Davoudi ${ }^{1, *} ;$ Jamshid Yazdani $^{3}$ \\ ${ }_{1}^{1}$ Department of Infectious Diseases and Tropical Medicine, Antimicrobial Resistance Research Center, Mazandaran University of Medical Sciences, Sari, IR Iran \\ ${ }^{2}$ Faculty of Medicine, Mazandaran University of Medical Sciences, Sari, IR Iran \\ ${ }^{3}$ Department of Biostatistics, Health Sciences Research Center, Faculty of Health, Mazandaran University of Medical Sciences, Sari, IR Iran \\ ${ }^{*}$ Corresponding Author: Alireza Davoudi, Department of Infectious Diseases and Tropical Medicine, Antimicrobial Resistance Research Center, Mazandaran University of Medical \\ Sciences, Sari, IR Iran. Tel:+98-1232316319, Fax:+98-1232316319, E-mail: eiy_iran@yahoo.com
}

Received: November 9, 2013; Revised: January 21, 2014; Accepted: February 24, 2014

\begin{abstract}
Background:Thrombocytopenia is associated with a bad prognosis in Leptospirosis.
Objectives: We investigated the effect of corticosteroids to improve thrombocytopenia due to leptospirosis.

Patients and Methods: In a clinical trial, all patients admitted with leptospirosis in Razi Hospital of Ghaemshahr, north of Iran were enrolled in a 2-year study. Totally, 56 patients with moderate to severe thrombocytopenia were randomized to control and treatment groups. The treatment group received corticosteroid (prednisolone $1 \mathrm{mg} / \mathrm{kg} /$ day for maximum one week) in addition to the standard antibiotic therapy.

Results: There was no significant difference regarding age and gender between the two groups $(P=0.254, P=0.789$, respectively). The mean duration to improve thrombocytopenia was $4.41 \pm 0.197$ days in the treatment group and $5.72 \pm 0.318$ days in the control group, which was significantly different $(\mathrm{P}=0.003)$. Duration of hospitalization in the treatment group was $5.24 \pm 0.244$ days and $6.23 \pm 0.329$ days in the control group, which was significantly different $(\mathrm{P}=0.028)$. The two groups had no significant difference regarding mortality, intubation, level of platelet, duration of ICU admission and pulmonary, renal or hepatic involvement.

Conclusions: Corticosteroid therapy decreased the length of hospitalization only in severe subgroup thrombocytopenia, but not in the moderate subgroup.
\end{abstract}

Keywords:Leptospirosis; Thrombocytopenia; Corticosteroids

\section{Background}

Leptospirosis is a zoonotic infection in humans and animals caused by Leptospira species of the spirochete family (1). There are two stages in the disease process. The first phase occurs during the active leptospira infection named as bacteriemic or septicemic phase. In this phase, flu-like symptoms (including fever, severe headache, myalgia, chills, nausea and vomiting, conjunctival suffusion, abdominal pain, anorexia, coughing and sore throat) occur for more than 5-7 days. The second phase, immunologic, occurs immediately after the bacteriemic phase or 1-3 days after asymptomatic period. Patient's symptoms vary in this phase. Many patients have mild fever, headache, vomiting and rash. Aseptic meningitis is most common in the second phase. Ten percent of patients with leptospirosis are affected by a severe form of disease or Weil's syndrome (with a mortality rate of 5-40\%) (2). Common symptoms of this syndrome are due to liver, kidney and blood vessels involvement. Symptoms of this severe disease occur after 3 to 7 days and include persistent jaundice, decreased urine output, anemia, rash, hypotension, shock, changes in consciousness, skin and mucosal hemorrhagic lesions and pulmonary hemorrhage (1-6). On entering the body, there is widespread hematogenous dissemination and penetration of tissue barriers, including invasion to the central nervous system and aqueous humor of the eye. Transendothelial migration of spirochetes is facilitated by a systemic vasculitis, accounting for a broad spectrum of clinical illness $(2,7)$. Severe vascular injury can be developed, leading to pulmonary hemorrhage, ischemia of the renal cortex and tubular-epithelial cell necrosis, and destruction of the hepatic architecture, resulting in jaundice and liver cell injury, with or without necrosis (2, 8-11). Immune-mediated mechanisms have been postulated to affect the severity of symptoms and immune mechanisms, including circulating immune complexes, anticardiolipin antibodies, and antiplatelet antibodies, but their significance has not been proven yet (2). Old age, pneumonia, renal failure, and thrombocytopenia are associated with a bad prognosis (1). Thrombocytopenia occurs in the absence of disseminated intravascular coagulation and may accompany progressive renal dysfunction (2).

\section{Objectives}

In this study, we investigated the role of corticosteroids to improve thrombocytopenia due to leptospirosis.

Copyright (C) 2014, Iranian Red Crescent Medical Journal; Published by Kowsar. This is an open-access article distributed under the terms of the Creative Commons Attribution-NonCommercial 4.0 International License (http://creativecommons.org/licenses/by-nc/4.0/) which permits copy and redistribute the material just in noncommercial usages, provided the original work is properly cited. 
Alian S et al.

\section{Patients and Methods}

This study was a randomized double-blind clinical trial. This study was approved by the Ethics Committee of Mazandaran University of Medical Sciences (Code No: 9186, Date: December 19, 2012). The sample size in each group was calculated based on previous studies including that performed by Villanueva et al. (12). The sample size was calculated as 22 based on the following formula, but we enrolled 56 patients.

$$
\begin{aligned}
& \mathrm{n}=\left(2 \times\left(\mathrm{Z}_{1-\alpha / 2}+\mathrm{Z}_{1-\beta}\right)^{2} \times \sigma^{2}\right) /\left(\mu_{1}-\mu_{2}\right)^{2}=22 \\
& \mu_{1}=8.3, \mu_{2}=7.6, \alpha=0.05, \beta=0.2, \sigma^{2}=0.0625 .
\end{aligned}
$$

Totally, 187 patients were admitted as leptospirosis based on clinical and epidemiologic criteria in Razi Hospital of Ghaemshahr, north of Iran from August 2011 to September 2013 (two years) (serology tests had not positive results in all cases, those patients diagnosed clinically with false negative serology results were excluded). Razi Hospital is a governmental and teaching hospital with 200 beds. Infectious disease ward is a referral ward in Mazandaran province. Thrombocytopenia was classified to mild (PLT < 150000), moderate (PLT < 100000) and severe $(\mathrm{PLT}<50000)$. Platelet count had normal findings in 17 patients and 98 cases had mild thrombocytopenia and thus excluded. The remaining 72 patients with moderate to severe thrombocytopenia were enrolled. Patients who met the inclusion criteria were randomized to control and treatment groups. We applied simple randomization method. The treatment group received corticosteroid (prednisolone $1 \mathrm{mg} / \mathrm{kg} /$ day) in addition to antibiotic therapy (ceftriaxone $1 \mathrm{~g} / \mathrm{Iv} /$ daily) until improvement of thrombocytopenia or for a maximum one-week and the control group received the same dosage of antibiotics, but received placebo instead of corticosteroid during this period. Exclusion criteria were patients with negative MAT or those with any health-threatening complications caused by corticosteroid or patients who had previous intake of steroids or other antibiotics two weeks or less prior to the diagnosis of disease and patients whom their clinician did not administered steroids due to some compelling factors like hypersensitivity to steroids, and finally those who were not willing to participate. Sixteen patients due to absence of serologic evidence (MAT had negative results) were excluded and the final analysis was performed on 56 patients in two divided groups. Statistical analysis was performed by independent T-test, Chi-Square, KaplanMeier, Log Rank and Breslau using SPSS software (version 13). To confirm the diagnosis of leptospirosis by MAT, $10 \mathrm{~mL}$ blood sample of each patient was obtained. Serum was separated immediately and poured into a sterile polypropylene tube and sent to the Reference Laboratory of Hisarak while maintaining the cold chain. Patients were visited daily and monitored closely. Laboratory changes in patients, including platelet count were check daily. Patients were followed up until discharge (Tables 1 and 2).

\section{Results}

Patients' age in the two groups (cases and controls) was compared using independent T-test, which had no significant difference $(P=0.254)$. The average age in case group was $49.75 \pm 8.45$ and $46.68 \pm 11.26$ years in the control group. Gender was assessed using Chi-Square test, which revealed no statistical difference between the two groups $(\mathrm{P}=0.789)$. Treatment group included 14 females and 14 males and control group 13 females and 15 males. Time needed for the improvement of thrombocytopenia was evaluated in the two groups using Kaplan-Meier and Log Rank Test. The treatment group required a mean duration of $4.41 \pm 0.197$ days and the control group $5.72 \pm$ 0.318 days. The treatment group had a median of $4 \pm 0.215$ days and the control group $5 \pm 0.255$ days (Log Rank was 8.625), which was statistically significant $(P=0.003)$ (degree of freedom $(\mathrm{DF})=1$ ) (Figure 1 and Table 3 ).

Duration of hospitalization in the two groups was compared using Kaplan-Meier, Log Rank and Breslau Test. The treatment group had a mean of $5.24 \pm 0.244$ days and the control group $6.23 \pm 0.329$ days. The treatment group had a median of $5 \pm 0.221$ days and the control group 6 \pm 0.297 days (Log Rank was 4.825); therefore, there was a significant difference between them $(\mathrm{P}=0.028), \mathrm{DF}=$ 1 and Breslau $=4.916$ with $\mathrm{DF}=1$ and $\mathrm{P}=0.027$ (Figure 2 and Table 3).

There was no significant difference between the two groups regarding mortality rate, intubation, platelet count, duration of ICU admission, and pulmonary, renal or hepatic involvement. In our study, five patients expired including two patients in the case group (one in moderate thrombocytopenia subgroup and the other in the severe thrombocytopenia

Table 1. Patients Characteristics

\begin{tabular}{|lc}
\hline Characteristics & No. \\
\hline Suspected Patients & 187 \\
\hline Thrombocytopenia & 17 \\
\hline Negative & 170 \\
\hline Positive & \\
\hline Severity of Thrombocytopenia & 98 \\
\hline Mild & 72 \\
\hline Moderate \& severe & \\
\hline Serology & 16 \\
\hline Negative & 56 \\
\hline Positive & 28 \\
\hline Groups & \\
\hline Case & 28 \\
\hline Control & \\
\hline
\end{tabular}


Table 2. Distribution of Patients in Moderate and Severe Subgroups

\begin{tabular}{lccc}
\hline Thrombocytopenia & Case & Control & Total \\
\hline Moderate & 15 & 19 & 34 \\
Sever & 13 & 9 & 22 \\
Total & 28 & 28 & 56 \\
\hline
\end{tabular}

subgroup) and three in the control group (all in the severe thrombocytopenia subgroup). One died due to acute renal failure and others died due to multiorgan failure. The two groups were divided into two subgroups according to the severity of thrombocytopenia (Table 2 ) as moderate $(50000<$ PLT $<100000)$ and severe (PLT $<50000)$. The two subgroups of moderate and severe thrombocytopenia were compared regarding required time for thrombocytopenia improvement; P-values in moderate and severe subgroup were 0.016 and 0.001 , respectively, which was statistically significant. Besides, duration of hospital stay was compared between moderate and severe subgroups using Brislow test; P-values were 0.06 and 0.006, respectively, there was no significant differences in moderate group, but the group there were severe a statistical difference was significant (Table 3 ). There was no significant difference between the two subgroups (moderate and severe thrombocytopenia) between the case and control groups regarding mortality, intubation, length of stay in ICU, pulmonary, renal or hepatic involvement and platelets count.

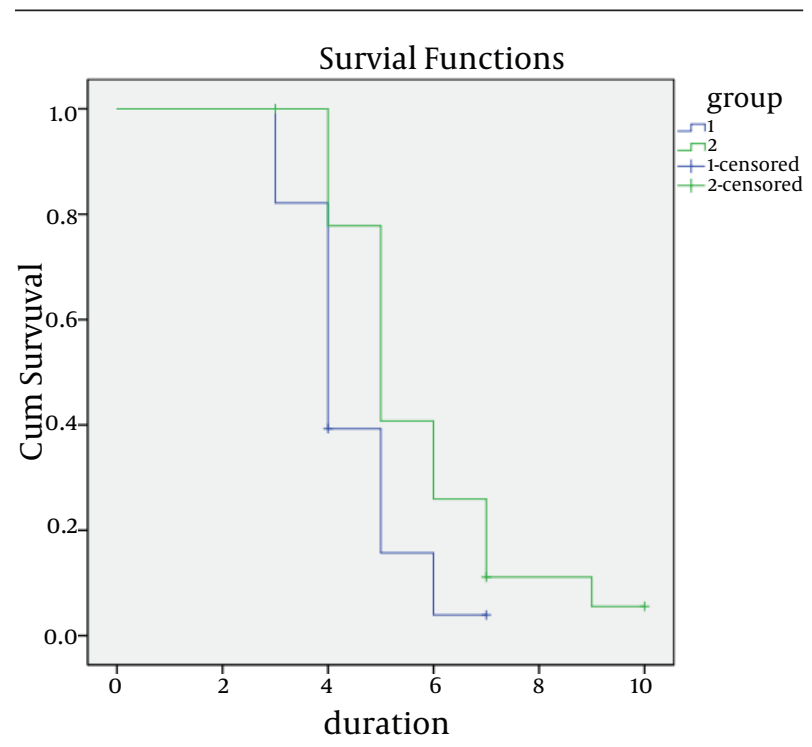

Figure 1. Survival Function Regarding Required Duration for the Improvement of Thrombocytopenia in the Two Groups

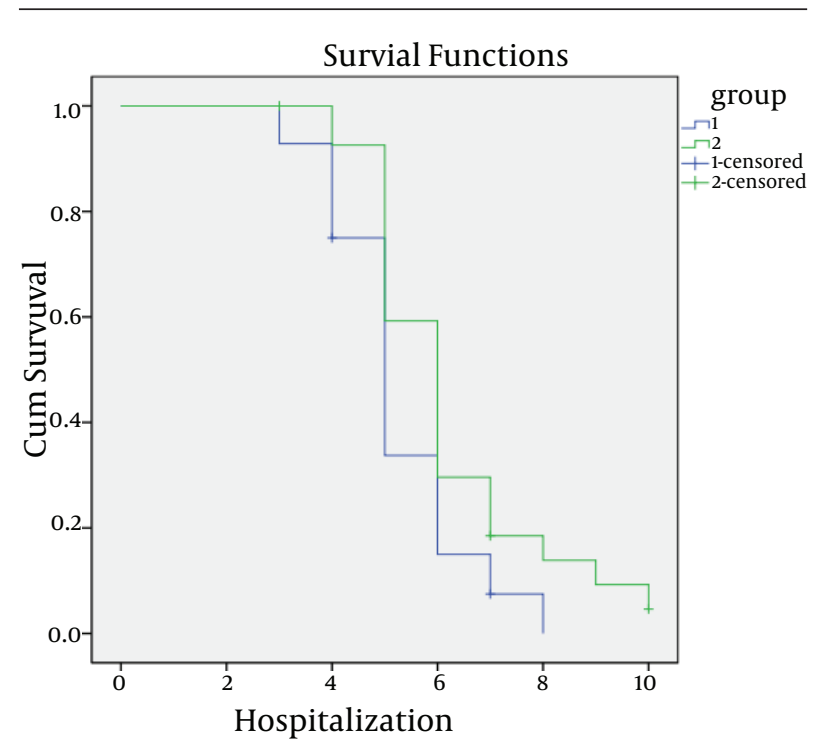

Figure 2. Survival Function Regarding Duration of Hospitalization in the Two Groups

Table 3. Statistical Analysis Regarding Improvement of Thrombocytopenia and Length of Hospitalization

\begin{tabular}{|c|c|c|c|c|}
\hline Group & $\begin{array}{c}\text { Mean/M. } \\
\text { Rank }\end{array}$ & Median & $\begin{array}{c}\text { Breslau/Log } \\
\text { Rank }\end{array}$ & PValue \\
\hline Duration $^{\mathrm{a}}$ & & & 8.626 & 0.003 \\
\hline Case & 4.411 & 4.000 & & \\
\hline Control & 5.722 & 5.000 & & \\
\hline Moderate & & & 5.779 & 0.016 \\
\hline Case & 4.200 & 4.000 & & \\
\hline Control & 4.947 & 5.000 & & \\
\hline Severe & & & 12.035 & 0.001 \\
\hline Case & 4.641 & 5.000 & & \\
\hline Control & 7.563 & 7.000 & & \\
\hline Hospitalization $^{b}$ & & & 4.916 & 0.027 \\
\hline Case & 5.241 & 5.000 & & \\
\hline Control & 6.231 & 6.000 & & \\
\hline Moderate & & & 3.546 & 0.060 \\
\hline Case & 4.800 & 5.000 & & \\
\hline Control & 5.579 & 5.000 & & \\
\hline Severe & & & 7.505 & 0.006 \\
\hline Case & 5.678 & 6.000 & & \\
\hline Control & 7.875 & 7.000 & & \\
\hline
\end{tabular}


Alian S et al.

\begin{tabular}{|c|c|c|c|c|}
\hline Group/Analysis Variable & Received Corticosteroid Group & $\begin{array}{l}\text { Not-received Corticosteroid } \\
\text { Group }\end{array}$ & P-Value & $\begin{array}{c}\text { Total } \\
\text { Frequency }\end{array}$ \\
\hline Number of Patients & 28 & 28 & & $56(100)$ \\
\hline Moderate Thrombocytopenia & 15 & 19 & & $34(60.7)$ \\
\hline Severe Thrombocytopenia & 13 & 9 & & $22(39.2)$ \\
\hline Gender & & & 0.789 & \\
\hline Female & 14 & 13 & & \\
\hline Male & 14 & 15 & & \\
\hline Age & $49.75 \pm 8.45$ & $46.68 \pm 11.26$ & 0.254 & \\
\hline Kidney involvement & $5(17.9)$ & $5(17.9)$ & 1.000 & \\
\hline Lung involvement & $5(17.9)$ & $6(21.4)$ & 0.737 & \\
\hline Liver involvement & $9(32.1)$ & $12(42.9)$ & 0.408 & \\
\hline Intubation & $4(14.2)$ & $4(14.2)$ & 1.000 & \\
\hline Mortality & $2(7.1)$ & $3(10.7)$ & 0.500 & \\
\hline ICU admission, Mean Rank & 28.02 & 28.98 & 0.758 & \\
\hline \multicolumn{5}{|l|}{ Dialysis } \\
\hline Platelet Consumption, Mean Rank & 27.79 & 29.21 & 0.568 & \\
\hline Duration $^{\mathrm{b}}$ & & & 0.003 & \\
\hline Mean & $4.41 \pm 0.197$ & $5.72 \pm 0.318$ & & \\
\hline Median & $4 \pm 0.215$ & $5 \pm 0.255$ & & \\
\hline Hospitalization $^{c}$ & & & 0.028 & \\
\hline Mean & $5.24 \pm 0.244$ & $6.23 \pm 0.329$ & & \\
\hline Median & $5 \pm 0.221$ & $6 \pm 0.297$ & & \\
\hline Rural & $24(85.7)$ & $24(85.7)$ & & $48(85.7)$ \\
\hline Farmer & $24(85.7)$ & $25(89.2)$ & & $49(87.5)$ \\
\hline Weakness & $28(100)$ & $28(100)$ & & $56(100)$ \\
\hline Fever & $28(100)$ & $28(100)$ & & $56(100)$ \\
\hline Anorexia & $20(71)$ & $20(71)$ & & $40(71.4)$ \\
\hline Myalgia & $25(89.28)$ & $24(85.71)$ & & $49(87.5)$ \\
\hline Arthralgia & $20(71.42)$ & $20(71.42)$ & & $40(71.4)$ \\
\hline $\mathrm{N} / \mathrm{V}$ & $9(32.1)$ & $7(25)$ & & $16(28.5)$ \\
\hline Cough & $6(21.4)$ & $5(17.8)$ & & $11(19.6)$ \\
\hline Headache & $7(25)$ & $7(25)$ & & $14(25)$ \\
\hline Abdominal pain & $5(17.8)$ & $5(17.8)$ & & $10(17.8)$ \\
\hline Hemoptysis & $1(3.5)$ & $2(7.1)$ & & $3(5.35)$ \\
\hline Diarrhea & $2(7.1)$ & $2(7.1)$ & & $4(7.1)$ \\
\hline Hypotension & $3(10.7)$ & $3(10.7)$ & & $6(10.7)$ \\
\hline Tachypnea & $5(17.8)$ & $6(21.4)$ & & $11(19.6)$ \\
\hline Tachycardia & $9(32.1)$ & $9(32.1)$ & & $18(32.1)$ \\
\hline LOC & $2(7.1)$ & $3(10.7)$ & & $5(8.9)$ \\
\hline Fever blister & $8(28.5)$ & $8(28.5)$ & & $16(28.5)$ \\
\hline Rash & $5(17.8)$ & $5(17.8)$ & & $10(17.8)$ \\
\hline Suffusion & $11(39.2)$ & $12(42.8)$ & & $23(41.0)$ \\
\hline Icter & $9(32.1)$ & $12(42.8)$ & & $21(37.5)$ \\
\hline LAP & 0 & $1(3.5)$ & & $1(1.7)$ \\
\hline Rales & $4(14.2)$ & $4(14.2)$ & & $8(14.2)$ \\
\hline Abdominal tenderness & $5(17.8)$ & $6(21.4)$ & & $11(19.6)$ \\
\hline Splenomegaly & $2(7.1)$ & $3(10.7)$ & & $5(8.9)$ \\
\hline Hepatomegaly & 0 & $1(3.5)$ & & $1(1.7)$ \\
\hline Muscular tenderness & $10(35.7)$ & $10(35.7)$ & & $20(35.7)$ \\
\hline Arrhythmia & $1(3.5)$ & 0 & & $1(1.7)$ \\
\hline Oliguria & $5(17.8)$ & $5(17.8)$ & & $10(17.8)$ \\
\hline EKG Changes & $2(7.1)$ & $1(3.5)$ & & $3(5.35)$ \\
\hline CXR Changes & $5(17.8)$ & $7(25)$ & & $12(21.4)$ \\
\hline
\end{tabular}


Alian $S$ et al.

\begin{tabular}{lccc}
\hline Leukocytosis & $6(21.4)$ & $8(28.5)$ & $14(25)$ \\
Leucopenia & $1(3.5)$ & $3(10.7)$ & $4(7.1)$ \\
Azotemia & $5(17.8)$ & $5(17.8)$ & $10(17.8)$ \\
Hyperglycemia & $2(7.1)$ & $3(10.7)$ & $5(8.9)$ \\
Hypoglycemia & 0 & $6(21.4)$ & 0 \\
Hyperkalemia & $5(17.8)$ & $5(17.8)$ & $7(19.6)$ \\
Hypokalemia & $5(17.8)$ & & $10(17.8)$ \\
Hematuria & $5(17.8)$ & & 12 \\
ESR, Total mean & $30.20 \pm 19.323$ & & \\
CRP, Total mean & $0.86 \pm 0.724(0-2$ plus $)$ & & \\
INR, Total mean & $1.10 \pm 0.128$ & & \\
BILL-T, Total mean & $4.675 \pm 4.1387$ & & \\
BILL-D, Total mean & $1.996 \pm 2.0695$ & & \\
AST, Total mean & $114.75 \pm 89.278$ & & \\
ALT, Total mean & $125.93 \pm 91.229$ & & \\
ALK.P, Total mean & $374.07 \pm 131.135$ & & \\
\hline
\end{tabular}

a Abbreviations: ICU, intensive care unit; CXR, chest x-ray; N/V, nausea and vomiting; LOC, decreased level of consciousness; LAP, lymphadenopathy; ESR, erythrocyte sedimentation rate; CRP, C-reactive protein; INR, international normalized ratio; BILL-T, bilirubin-total; BILL-D, bilirubin-direct; AST, aspartate aminotransferase; ALT, alanine aminotransferase; ALK.P, alkaline phosphatase.

$\mathrm{b}$ Duration = Duration in days required for the improvement of thrombocytopenia.

${ }^{\mathrm{C}}$ Hospitalization $=$ length of hospital stay (in days).

\section{Discussion}

There was no significant difference between the two groups regarding renal, pulmonary or hepatic involvement, intubation, mortality rate and hospitalization duration in ICU. The above situations were not improved with treatment of glucocorticoid. Despite the fact, required duration for the improvement of thrombocytopenia and duration of hospitalization in two groups were different significantly. On the other hand, treatment with glucocorticoid caused more rapid recovery of thrombocytopenia and shorter hospital stay. Corticosteroids have an essential role in the treatment of many immune-associated diseases, such as SLE, rheumatoid arthritis (RA) and ITP. Prednisolone ( $1 \mathrm{mg} / \mathrm{kg} /$ day) is used for the treatment of mild ITP (Immune or Idiopathic Thrombocytopenic Purpura); while, high-dose corticosteroid (steroid pulse therapy) is used for the severe forms $(1,13)$. Russell Villanueva et al. in the Philippines, performed an investigation on 36 patients with leptospirosis and found no significant reduction in mortality, duration of hospitalization and dialysis rates between the control and steroids groups (12). Furthermore, a study by Trivedi et al. in India performed on 602 patients showed that renal and liver involvements had no effect on mortality (14). Similarly, in this study, statistical analysis showed that renal, lung or liver involvements and the severity of thrombocytopenia had no effect on mortality. Contrary to our results, a clinical trial on 30 patients by VV Shenoy et al. in India showed that corticosteroid therapy within 12 hours of pulmonary involvement due to leptospirosis decreased the mortality rate (15).

Our study showed that corticosteroid therapy decreased hospital stay only in severe subgroup thrombocytopenia (not in the moderate subgroup). To optimally determine whether adjunctive steroid use in leptospirosis is beneficial, an adequately powered randomized control trial with a larger sample size is recommended.

\section{Acknowledgements}

We would like to thank nurses of the infection diseases Ward of Ghaemshahr Razi Hospital to help in data collection.

\section{Authors' Contributions}

Study concept and design: Shahriar Alian, Alireza Davoudi, Narges Najafi, Hasan Asghari, Jamshid Yazdani. Acquisition of data: Shahriar Alian, Hasan Asghari, Alireza Davoudi. Analysis and interpretation of data: Hasan Asghari, Jamshid Yazdani. Drafting of the manuscript: Alireza Davoudi. Critical revision of the manuscript for important intellectual content: Narges Najafi. Statistical analysis: Jamshid Yazdani.

\section{Funding/Support}

This project was supported by a grant received from the Vice-Chancellor for research of Mazandaran University of Medical Sciences.

\section{References}

1. Speelman P. leptospirosis. In: Braunwald E, Fauci A, kasper D editors. Harrison's principles of Internal Medicine. New York: McGrawHill; 2012.

2. Levett P. Leptospira species. In: Mandell GL, Bennett JE, Dolin R editors. principles and practice of infectious disease. 7th ed; 2010. pp. 3059-65. 


\section{Alian S et al.}

3. Mansour-Ghanaei F, Sarshad A, Fallah MS, Pourhabibi A Pourhabibi K, Yousefi-Mashhoor M. Leptospirosis in Guilan, a northern province of Iran: assessment of the clinical presentation of 74 cases. Med Sci Monit. 2005;11(5):CR219-23.

4. Bharti AR, Nally JE, Ricaldi JN, Matthias MA, Diaz MM, Lovett MA, et al. Leptospirosis: a zoonotic disease of global importance. Lancet Infect Dis. 2003;3(12):757-71.

5. Kuo HL, Lin CL, Huang CC. Reversible thick ascending limb dysfunction and aseptic meningitis syndrome: early manifestation in two leptospirosis patients. Ren Fail. 2003;25(4):639-46.

6. Aliyan S, Babamahmoodi F, Najafi N, Ghasemian R, Teymori S, Shahbaznezhad L. Clinical and paraclinical findings of leptospirosis in Mazandaran. J Mazandaran Univ Med Sci. 2006;16:78-85.

7. Babamahmoodi F, Motamed N, Mahdavi MR, Nikkhah F, Ghavi Bonyeh KH. Seroepdemiological study of leptospirosis in GhaemshahrMazandaranprovinc. J Mazandaran Univ Med Sci. 2006;16:51-6.

8. Boland M, Sayers G, Coleman T, Bergin C, Sheehan N, Creamer E, et al. A cluster of leptospirosis cases in canoeists following a competition on the River Liffey. Epidemiol Infect. 2004;132(2):195-200.

9. Faucher JF, Hoen B, Estavoyer JM. The management of leptospiro- sis. Expert Opin Pharmacother. 2004;5(4):819-27.

10. Vitale G, La Russa C, Galioto A, Chifari N, Mocciaro C, Caruso R, et al. Evaluation of an IgM-ELISA test for the diagnosis of human leptospirosis. New Microbiol. 2004;27(2):149-54.

11. Yitzhaki S, Barnea A, Keysary A, Zahavy E. New approach for serological testing for leptospirosis by using detection of leptospira agglutination by flow cytometry light scatter analysis. J Clin Microbiol. 2004;42(4):1680-5.

12. Villanueva R, Onoya C, Esmiller F, Francisco M. Use of steroid in leptospirosis to improve survival: an exploratory study. Philipp J Microbiol Infectious Dis. 2010;39(1):71-5.

13. Trivedi SV, Vasava AH, Bhatia LC, Patel TC, Patel NK, Patel NT Plasma exchange with immunosuppression in pulmonary alveolar haemorrhage due to leptospirosis. Indian J Med Res. 2010;131:429-33.

14. Trivedi SV, Vasava AH, Patel TC, Bhatia LC. Cyclophosphamide in pulmonary alveolar hemorrhage due to leptospirosis. Indian J Crit Care Med. 2009;13(2):79-84.

15. Shenoy VV, Nagar VS, Chowdhury AA, Bhalgat PS, Juvale NI. Pulmonary leptospirosis: an excellent response to bolus methylprednisolone. Postgrad Med J. 2006;82(971):602-6. 